\title{
JAVIER ESQUIVEL, FILÓSOFO SOCRÁTICO *
}

\author{
C. ULISES MOULINES
}

UNIVERSIDAD LIBRE DE BERLÍN

A principios de 1976 arribé a México, país entonces casi desconocido para mí, del cual apenas sabía otra cosa sino que era (Octavio Paz dixit) un laberinto muy difícil de comprender. Mi primer contacto personal fue con Javier Esquivel. A las pocas horas de entablar conversación, habíamos tratado multitud de temas - desde la psicología profunda hasta la política internacional, desde la historia de México hasta el teorema de Gödel- y nos habíamos convertido en grandes amigos. Javier me abrió las puertas de México, y a él le debo en primera instancia que, a las pocas semanas, el inquietante laberinto se hubiera convertido en hogar acogedor, en la patria adoptiva que ha seguido siendo desde entonces. Por ello, la muerte de Javier Esquivel ha sido para mí doblemente dolorosa: significa la desaparición de un gran amigo y a la vez la pérdida de un guía insustituible, que acompañó mis pasos en una etapa importante de mi vida.

Todos los que conocieron a Javier saben de la profunda impresión que causaba en los demás. No es fácil definirla. Sin duda estribaba en su bondad natural, pero no era sólo eso; en su despierta inteligencia, pero no sólo eso; en su agudeza y sentido del humor, pero no sólo eso. . . La hipótesis que quisiera adelantar aquí es que el atractivo peculiar que ejercía la personalidad de Javier (aunque probablemente ni él mismo ni los demás eran conscientes de ello) radicaba, en último término, en su carácter de filósofo genuino, en que se nos manifestaba como un personaje salido de la "leyenda áurea" de la filosofía antigua, uno de esos preguntones infatigables y criticones insobornables que imaginamos deambulando por las plazas de Atenas o Alejandría...

Desde la Antigüedad clásica se han dado dos modos de emprender el viaje filosófico, dos distintas vías filosóficas. Las podríamos denominar, en honor a sus primeros y más conspicuos representantes, la "vía socrática" y la "vía aristotélica". (Platón estaría, por así decir, a medio camino entre ambas, y no

* Este ensayo es una versión revisada y ampliada de un artículo previo destinado al Boletín del Centro Latinoamericano de Munich. 
sólo desde el punto de vista genealógico.) La vía aristotélica es la que hemos escogido la inmensa mayoría de quienes nos dedicamos profesionalmente a la filosofía. Consiste en ser miembro de una comunidad disciplinaria (en la Antigüedad, el "Liceo"; hoy día, las universidades), que funciona de manera bastante parecida a las comunidades científicas, y en la que lo primordial de la actividad filosófica consiste en la publicación de ensayos, tratados, manuales; en una palabra, en la obra escrita. La personalidad y el decurso vital del filosofante tienen en la vía aristotélica mucho menor relieve que su obra.

La relación entre vida y obra en la vía socrática, en cambio, es exactamente la inversa. Por lo que sabemos, Sócrates no escribió ni una sola línea filosófica en.toda su vida. Lo que hacía era pasear y hacerse a sí mismo y a los demás preguntas enojosas. Su vida misma (y su muerte) es el filosofema más importante que nos legó. Por la naturaleza propia de la vía socrática, es muy improbable que quien la escoja llegue a ser ampliamente conocido. $\mathrm{Si}$ no hubiera sido por las "reconstrucciones" literarias de Sócrates que nos han transmitido Platón y Jenofonte, nada sabríamos de él, excepto quizás que era un oscuro personaje ridiculizado en una comedia burlesca de Aristófanes. En la historia intelectual de nuestra cultura habrá habido seguramente un gran número de filósofos socráticos a quienes se los ha tragado la noche del olvido. Y probablemente la mayoría de ellos no tenía ningún problema en que ello fuera así. Pues su objetivo no era darse a conocer comunicando a un público amplio, mediante ensayos o tratados, los resultados de sus investigaciones, sino hallar el modo, a través del incesante diálogo con un reducido grupo de amigos, de vivir la buena vida — una vida acorde con sus convicciones éticas y metafísicas más profundas. Si el objetivo básico del filósofo aristotélico puede resumirse en el lema "conoce la verdad sobre el mundo", la del filósofo socrático es, como sabemos, "conócete a tí mismo".

Javier Esquivel es el filósofo socrático más notable que he conocido en mi vida, en el transcurso de mis andanzas por media docena de países de dos continentes. Estoy convencido, además, de que la mayoría de colegas hispanohablantes o alemanes que lo hayan conocido de modo algo más que superficial, coincidirán con mi apreciación. Desde el primer momento en que lo conocí me percaté de su inigualable capacidad para llegar al fondo de cualquier cuestión planteada. iCuántos de nosotros, en México, Alemania o en otros países, no hemos gozado incontables veces de lo que él llamaba "un seminario" - - esos debates en un pequeño círculo de tres o cuatro amigos, que podían durar toda una tarde o toda una noche y en los que Javier, con su invariable modestia, dirigía, cual "mano invisible" y sin que nos percatáramos realmente, el curso del diálogo! En esos debates filosóficos cualquier tema, sin ningún tabú y sin ninguna concesión a 
posibles susceptibilidades, podía ser objeto de análisis radical —desde los más excelsos y tradicionales de la metafísica (la existencia de Dios, la vida más allá de la muerte, la identidad del yo...) hasta los más concretos de la vida moral y política (¿cuándo está justificada la guerra?; ¿cómo planearías el resto de tu vida hoy lunes si supieras que el próximo domingo necesariamente has de morir?; ies moralmente permisible en la actualidad engendrar hijos?... ). Ninguna cuestión, por complicada conceptualmente o irritante moralmente que pareciese, dejaba de ser tratada hasta su último recoveco, en todos sus aspectos, desde todo punto de vista. Los "seminarios" de Esquivel permanecerán grabados en mi memoria como las experiencias colectivas de hacer filosofía más enriquecedoras de mi vida, y creo que así lo experimentaron también muchos otros de sus amigos.

Por supuesto que, como bien saben los colegas mexicanos, Javier Esquivel también anduvo un buen trecho por la vía aristotélica, por la vía académica. Cuando lo conocí, era miembro del Instituto de Investigaciones Filosóficas de la UNAM, donde, además de sus labores de investigación y docencia, ejercía el cargo de Secretario Académico. Pude constatar así que, a sus grandes cualidades intelectuales y morales, Javier unía dotes "prácticas" (poco comunes en alguien aparentemente tan "metafísico") de hábil organizador de las instituciones académicas. Sin duda habría llegado a ser años después un excelente director del Instituto si no hubiera decidido él mismo darle un giro drástico al curso de su vida.

Por aquellos primeros años en que lo conocí, Javier había publicado ya algunos ensayos sobre filosofía moral y política en revistas especializadas del mundo hispanohablante tales como Crítica, Diánoia, Teorema y otras. Poco después publicó su libro Kelsen y Ross, formalismo y realismo en la teoría del derecho (UNAM, México, 1980). Todos sus escritos, y en especial el libro mencionado, destacan por la inobjetable claridad de la exposición y por el rigor de la argumentación: un estilo académico en el mejor sentido de la palabra. El principal campo de intereses en su obra publicada fue la filosofía moral y política, aunque no descuidó por completo otros temas. Así, hacia el final de su carrera académica, publicó una antología de diversos autores hispanohablantes sobre el materialismo (La polémica del materialismo, Tecnos, Madrid, 1982), que causó cierto revuelo en el mundo filosófico iberoamericano de esos años.

Su inteligencia natural, su vastísima cultura, su disciplina de trabajo y por encima de todo su absoluta vocación filosófica parecían predeterminarlo hacia una brillante carrera académica. Si Javier hubiera proseguido por la "vía aristotélica" sin duda se habría convertido en un filósofo altamente reconocido en el mundo académico hispanohablante... Sin embargo, "se rebeló" contra lo que parecía su destino. A principios de la década de los 
80 nos comunicó que había decidido abandonar de una vez por todas la filosofía (académica) porque ella no satisfacía su más genuino interés vital: "encontrarse a sí mismo". Poco después decidió trasladarse definitivamente a Munich para incorporarse a un grupo con el que coincidía en esa orientación vital. Allí permaneció, viviendo en duras condiciones materiales, hasta su muerte.

Desde el principio hasta el fin pensé que esa decisión había sido equivocada, que había equivalido a tomar un camino que no conducía a ninguna parte. Por supuesto que así se lo manifesté a Javier más de una vez. Mi inquebrantable amistad, mi admiración por sus cualidades morales e intelectuales, nunca me impidieron expresarle mi opinión, aunque ésta no fuera "amable". Y claro que él me compensaba con la misma moneda. Por lo demás, ésta es la marca de la verdadera amistad: disentir radicalmente sobre alguna cuestión, plantear la divergencia abiertamente y, no obstante, preservar la amistad íntegra.

En cualquier caso, nunca compartí la idea que tenía Javier de "buscarse a sí mismo" (y al escribir estas líneas me parece estar discutiendo de viva voz con él, lo cual es también un modo de conservar su entrañable memoria). No creo en general en la idea de "buscarse a sí mismo" porque no creo que haya nada ahí que encontrar; o bien, en caso de que algo encontremos, no será nada muy edificante - un atajo más bien lamentable e incoherente de recuerdos paralizantes, ilusiones absurdas y emociones vergonzantes. Hasta cierto punto, Javier coincidía con esta visión de lo que uno puede hallar "buscándose a sí mismo": naturalmente que él no esperaba encontrarse finalmente con un alma cristalina, o con la divinidad, o con algo parecido. No obstante, estaba convencido de que sólo "desempaquetando" ese miserable fardo podía uno llegar a vivir en paz consigo mismo, "salvarse". Éste era quizás el punto de disensión más fundamental entre nosotros; en definitiva, una cuestión de método: pues, en mi opinión, la mejor manera de llegar a vivir en paz consigo mismo (si uno realmente quiere eso, lo cual tampoco tiene por qué ser el caso) no estriba en sumergirse en las propias entrañas, de las que probablemente nunca se vuelva a emerger, sino en todo lo contrario: olvidarse lo más posible de uno mismo; sólo así puede realmente alcanzarse la "paz perpetua"...

Sin embargo, a pesar de la profunda divergencia en este particular, siempre respeté, e incluso admiré, la tajante decisión que Javier había tomado de cortar por lo sano con lo que parecia su carrera predeterminada. Aunque yo considerara su camino equivocado, admiré la valentía, la coherencia con que Javier lo emprendió; por ningún concepto me pareció esa decisión motivo de burlas o de menosprecio. Fue una decisión auténtica. Es más, fue una decisión auténtica tomada por un auténtico filósofo, es decir, to- 
mada del modo como esperamos que un filósofo tome una decisión de esa envergadura.

En esta decisión radical desempeñaron sin duda un gran papel graves conflictos personales, de índole claramente no filosófica, por mucho que queramos estirar el término "filosofía". Sin embargo, fue también una decisión genuinamente filosófica. El modo usual de hacer filosofía dentro de una institución académica, con todas sus reglas, constricciones y rituales, simplemente no congeniaba con el espíritu de Esquivel. Pero ello no significaba en absoluto un desinterés por la filosofía "pura y dura". Prueba de ello es que, a pesar del radical cambio dado a su vida y de las condiciones sumamente adversas, Javier nunca dejó de interesarse por temas filosóficos, como pude constatar en numerosas ocasiones en que coincidimos aquí en Alemania. Sus "seminarios" siguieron siendo para mí, y para los demás participantes ocasionales, tan estimulantes y agudos como siempre. Cuando nos vimos por última vez un par de semanas antes de su muerte, volvimos a tener largas discusiones, arrebatadas y "cerebrales" a la vez, sobre cuestiones tales como la falta de objetividad en la historia, lo que puede significar la identidad latinoamericana, si hay que estarle agradecido o no a la bomba atómica... El último libro que vi en sus manos fue un sesudo estudio sobre Wittgenstein, uno de los filósofos contemporáneos que más le atraían, aunque del que opinaba (creo que con razón) que no había logrado poner su vida moral a la altura de su fuerza intelectual.

Todos los que conocimos a Javier Esquivel hemos perdido con él a un interlocutor incomparable, a un defensor de causas difíciles, a un amigo fiel y entrañable. Y, además, hemos perdido a un gran filósofo... a nuestro Sócrates mexicano. Quizás estas líneas contribuyan a que perdure su memoria. 